\title{
Conflicting but close: Readers' integration of information sources as a function of their disagreement
}

\author{
Gaston Saux ${ }^{1}$ (D) Anne Britt ${ }^{2} \cdot$ Ludovic Le Bigot $^{3} \cdot$ Nicolas Vibert $^{4}$. \\ Debora Burin $^{5}$ - Jean-François Rouet ${ }^{4}$
}

Published online: 16 August 2016

(C) Psychonomic Society, Inc. 2016

\begin{abstract}
According to the documents model framework (Britt, Perfetti, Sandak, \& Rouet, 1999), readers' detection of contradictions within texts increases their integration of source-content links (i.e., who says what). This study examines whether conflict may also strengthen the relationship between the respective sources. In two experiments, participants read brief news reports containing two critical statements attributed to different sources. In half of the reports, the statements were consistent with each other, whereas in the other half they were discrepant. Participants were tested for source memory and source integration in an immediate itemrecognition task (Experiment 1) and a cued recall task (Experiments 1 and 2). In both experiments, discrepancies increased readers' memory for sources. We found that discrepant sources enhanced retrieval of the other source compared to consistent sources (using a delayed recall measure; Experiments 1 and 2). However, discrepant sources failed to prime the other source as evidenced in an online recognition measure (Experiment 1). We argue that discrepancies promot-
\end{abstract}

Gaston Saux

gsaux@psi.uba.ar

1 Consejo Nacional de Investigaciones Científicas y Técnicas (CONICET), Universidad Catolica Argentina, Buenos Aires, Argentina

2 Northern Illinois University, DeKalb, IL, USA

3 Universite de Poitiers, Poitiers, France

4 CNRS, Centre de Recherches sur la Cognition et l'Apprentissage (CERCA UMR7295), Universite de Poitiers, Poitiers, France

5 Consejo Nacional de Investigaciones Científicas y Técnicas (CONICET), Universidad de Buenos Aires, Buenos Aires, Argentina ed the construction of links between sources, but that integration did not take place during reading.

Keywords Discrepancies $\cdot$ Sources $\cdot$ Text $\cdot$ Recognition $\cdot$ Recall

Managing multiple perspectives is fast becoming a core aspect of reading in the Internet era (e.g., Britt, Richter, \& Rouet, 2014; Gernsbacher, 2014). Ordinary activities such as Googling the news, completing a scholarly assignment, or even selecting a hotel for a trip can now require that people reconcile multiple, potentially discrepant versions of the same basic information.

One key skill that people use to assimilate multiple viewpoints into an integrated representation is sourcing (e.g., Rouet, 2006). The term sourcing entails a range of activities involved in establishing relations between textual contents and the origin of those contents. In practical terms, sourcing refers to the reader's attempts to focus on, retrieve, mention, and/or endorse some sources over others when performing tasks based on either current or previous reading (Britt \& Rouet, 2012; Britt, Rouet, \& Braasch, 2013; Stadtler \& Bromme, 2014).

This study examines the effect of semantic contradictions between two pieces of information on readers' integration of the information sources (e.g., two characters in a story) in their memory representation. Previous research has found evidence that discrepancies prompt readers to include source-to-content links in their representation of the text (Braasch, Rouet, Vibert, \& Britt, 2012; Rouet, Le Bigot, de Pereyra, \& Britt, 2016). This study examines the hypothesis that discrepancies also prompt readers to strengthen the association between the sources issuing the conflicting statements. In other words, 
after reading two conflicting (vs. consistent) statements, are readers more likely to identify one of the sources involved in the discussion when given the other source as a cue? If so, how can text comprehension theory account for this phenomenon?

\section{Text comprehension as representation building}

Readers engaged in discourse comprehension will sequentially parse and integrate incoming pieces of information into a coherent representation of what the text is about. Theoretical models of discourse comprehension (e.g., Kintsch, 1998; Myers \& O'Brien, 1998; van den Broek, Young, Tzeng, \& Linderholm, 1999) generally assume that comprehension entails the activation of semantic nodes corresponding to textual and inferential information, building a moment-by-moment representation of the text. Two types of processes are common in these models (see van den Broek, Rapp, \& Kendeou, 2005): cohort activation (van den Broek et al., 1999), also called resonance (Myers \& O'Brien, 1998) or construction (Kintsch, 1998); and coherence-oriented processes (van den Broek et al., 1999), also called integration (Kintsch, 1998). As reading progresses, textual information activates concepts and their relations, spreading through the reader's knowledge base and building an episodic representation. In sequential processing cycles, concepts mentioned in the text reactivate information that has previously become associated to those concepts in earlier processing; spreading activation can also occur in the reader's semantic background knowledge. For their part, coherence building or integrative processes constrain the ongoing representation by determining whether particular standards of coherence or strategic demands of the task are met (e.g., maintaining global coherence), further changing the resulting representation by adding nodes or strengthening or modifying connections. Both types of processes can act in concert in a given processing cycle.

These representational assumptions have been linked to memory models (Goldman, Golden, \& van den Broek, 2007). Accordingly, memory tasks such as recognition and recall have been used to examine accessibility and relatedness among different pieces of information within the text representation. As in memory research, correct recognition of single words is associated with familiarity based on overall activation, whereas cued and free recall need additional retrieval processes to access a particular identifiable event (Nobel \& Shiffrin, 2001).

The detection of semantic inconsistencies has been widely used as a tool to probe what information is active at a particular moment during comprehension. The inconsistency paradigm (Albrecht \& O’Brien, 1993; O’Brien \& Albrecht, 1992) involves manipulating a target sentence to make it either coincide with or oppose a previous setting attribute, typically a passage from the same text. If readers slow down their reading when presented with an inconsistency as compared to a consistent condition, then it can be assumed that the incoming information does not fit in or contradicts the ongoing semantic representation (Kendeou, Smith, \& O’Brien, 2013).

The initial use of this technique concentrated mainly on whether readers detect the inconsistencies, but not so much on how they resolve them. In other words, the focus was on the identification of the inconsistency during reading rather than on the strategies that readers may use to restore consistency (see, however, van Oostendorp, 2002). Considering that inconsistencies do occur as part of naturalistic discourse comprehension, it would be valuable to further examine readers' resolution of inconsistencies both in terms of moment-tomoment processing and in terms of memory outcomes.

\section{Discrepancies, sourcing, and the documents model framework}

Recent research has tested the assumption that textual discrepancies might trigger readers' integration of text contents with their respective sources (i.e., who says what) as an attempt to regulate the perceived discrepancy. Braasch et al. (2012) presented brief fictitious news articles on various topics containing two sources (embedded characters) that made specific assertions about the situation depicted in the text. Consider the following example, in which two claims regarding the cause of a fire in a building are reported: "The detective claims that the fire in the warehouse was caused by a malfunction in the electrical circuit. However, a journalist asserts that a pyromaniac was arrested in the act." Braasch et al. manipulated the compatibility of the claims by making them either discrepant (the fire was the result of a malfunction in the electrical circuit/ a pyromaniac was arrested in the act) or consistent (e.g., the fire was the result of a sabotage in the electrical circuit/a pyromaniac was arrested in the act), and also explicitly associated two distinct embedded sources (the journalist and the detective) with each claim. The authors found that discrepancy affected source processing: Participants made more eye fixations and gazed for longer times at source areas of the text, they mentioned more sources in summaries, and they recalled more sources in a content-based cued-recall task when reading discrepant stories than when reading consistent stories.

To account for these results, Braasch et al. (2012) proposed the discrepancy-induced source comprehension (D-ISC) assumption: When information is discrepant and source information is available, the reader will increase the level of attention to and the evaluation of the source information, thus leading to stronger connections between contents and sources. In alignment with other theoretical proposals (e.g., Stadtler \& Bromme, 2014), the D-ISC hypothesis proposes that increased sourcing represents a mechanism to restore 
consistency by assigning each content piece to different viewpoints. In the example of the fire, this implies that sourcerelated traces (e.g., who said what) should be more salient when the sources disagree on the cause of the fire than when they agree.

Different studies have provided additional evidence for the D-ISC assumption. For example, Rouet et al. (2016) found that source citation was a prevalent strategy when summarizing texts containing discrepancies and that memory for sources was better for discrepant statements. Similarly, Strømsø and Bråten (2014) found that undergraduate students mentioned sources more often during a think-aloud task when presented with multiple documents making strong opposing claims. Finally, Paul et al. (2014) reported that, when interviewed about sourcing, teenagers spontaneously identified conflicting arguments as one of the reasons that made them look more at source information. Readers as young as seventh grade show increased sensitivity to source information when encountering discrepancies, as measured by patterns of eye movements, online summarizing, and recall data, though the general effect does increase with age (de Pereyra, Belkadi, Marbach, \& Rouet, 2014). Other studies have examined the role of mediating factors for sourcing when reading about conflicting topics, such as reading goals (e.g., Stadtler, Scharrer, Skodzik, \& Bromme, 2014), epistemic beliefs on the use of the Internet (e.g., Kammerer, Amann, \& Gerjets, 2015; Kammerer, Bråten, Gerjets, \& Strømsø, 2013), the perceived trustworthiness and authority of the website and the sources (e.g., Kammerer, Kalbfell, \& Gerjets, 2014; Keck, Kammerer, \& Starauschek, 2015), and formal features of the Web pages (e.g., Salmerón, Kammerer, \& García-Carrión, 2013).

Overall, these studies can be considered evidence that, if readers are given a chance to link discrepant statements to various sources, then they will. However, the D-ISC assumption stems from a larger theoretical proposal: the documents model framework (DMF; Britt et al., 1999; Britt \& Rouet, 2012; Perfetti, Rouet, \& Britt, 1999; Rouet, 2006), which includes additional processing and representational claims. Previous studies have mainly focused on the link between sources and their statements, but could the DMF support additional assumptions regarding the regulation of consistency in multisource texts?

The DMF includes an explanation of "how readers manage to integrate multiple and possibly conflicting sources of information into coherent memory representations" (Britt \& Rouet, 2012 , p. 283). One of its core assumptions is that sourcing adds layers to the memory representation of discourse. Thus, together with an elaboration of the text contents, readers can also activate features associated with communicative features, such as indexing who says what and whether sources agree with each other. In representational terms, this means that the reader may construct a node-link structure that connects sources with their contents (S-C links). Additionally, the
DMF proposes that readers construct links among sources themselves (S-S links; e.g., Perfetti et al., 1999). In the aforementioned example of the warehouse fire, this implies producing a representation of what happened (the fire) and what may have caused it (a malfunction/a sabotage/a pyromaniac), representing the detective and the journalist as sources of each claim, and finally connecting the sources together in an integrated whole, based on their agreement (i.e., they agree, they disagree, etc.). Figure 1 illustrates this explanation by presenting the warehouse fire example to the left and the theoretical proposal by the DMF to the right. The S-C link for the detective's claim is illustrated as the line between the node for the detective (circle) and the claim (rectangle). The S-S link is illustrated by the line between the two source nodes (detective and journalist).

Previous studies (e.g., Braasch et al., 2012) have focused on the influence of textual discrepancies on S-C links (i.e., who says what, or indexing who holds a specific assertion). In an attempt to extend the scope of the D-ISC claim, the experiments presented here examine the S-S link (i.e., who agrees/disagrees with whom, or the connection between the sources) as a function of discrepancy. Online evidence has shown that more attention is drawn online to source areas when discrepancies are detected (Braasch et al, 2012; de Pereyra, Belkadi, et al., 2014; Kammerer et al., 2014). More attention, however, does not necessarily result in the construction of S-S connections during reading. Linking source information can be considered a cognitively demanding task that takes place later on, using memory traces (Johnson, Hashtroudi, \& Lindsay, 1993). The use of immediate recognition and delayed-recall tasks at different moments of the procedure could shed some light on this issue. We assume that an immediate, online item-recognition task would tap an already existing activation during comprehension (e.g., McKoon \& Ratcliff, 1980), whereas a delayed-recall task would reflect the resulting representation including elaborations based on memory cues and task demands (e.g., Dooling \& Christiaansen, 1977).

\section{The present research}

We conducted two experiments to test whether discrepant statements result in better memory for source nodes and a stronger link between them.

Experiment 1 examined the activation of the source nodes and their association with two memory tasks: immediate item recognition and delayed cued recall. As stated before, both tasks are useful for testing different aspects of the accessibility and the association between two or more pieces of information. Whereas immediate recognition would reflect the overall activation at a given moment (McKoon \& Ratcliff, 1984), cued recall would be more pertinent to evaluate elaborative 


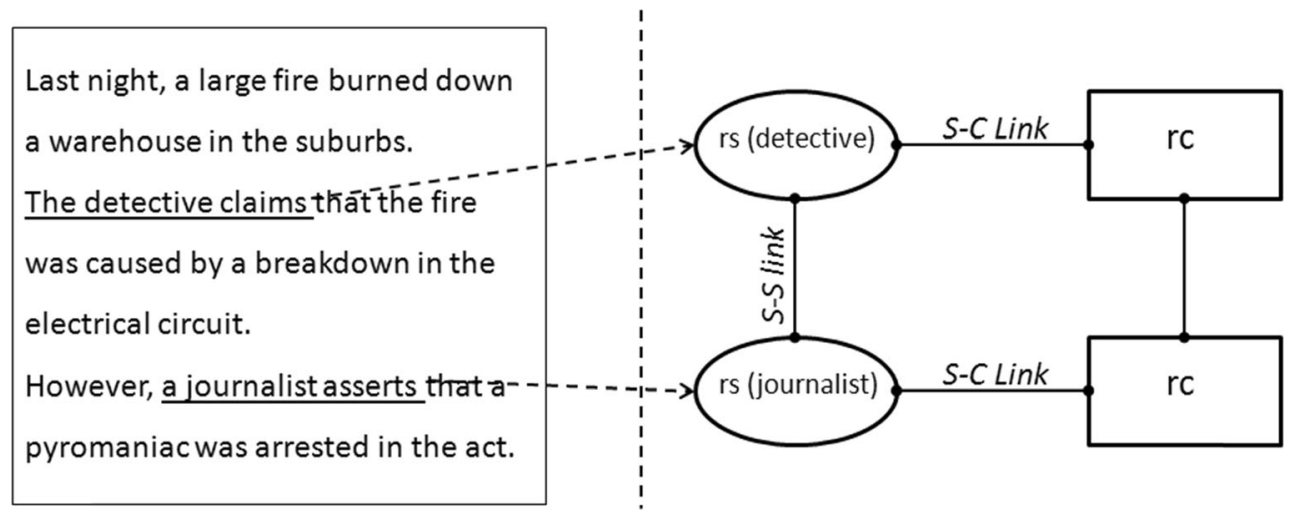

Fig. 1 Sources and contents integration in memory according to the documents model framework. $\mathrm{rs}(\mathrm{x})=$ representation of source; rc $(\mathrm{x})=\mathrm{representation}$ of content; S-C link: source-content link; S-S link: source-source link

processes that include reconstruction, the representation of the current task, and general knowledge (Nobel \& Shiffrin, 2001; Dooling \& Christiaansen, 1977). Therefore, we assumed that the immediate, time-constrained item-recognition task would indicate the state of activation and integration of source nodes during reading, whereas the cued-recall task would relate to the delayed access and elaboration of the S-S link. We manipulated discrepancy between the sources by presenting sentences that describe characters making either consistent or conflicting statements. The presentation of one of the characters then served as a cue for the recognition of the other source.

Experiment 2 addressed potential confounds in our first experiment. The specific goal was to rule out alternative explanations to the results observed in the cued-recall task from Experiment 1. First, the use of two subsequent memory tasks in Experiment 1 may have led to a testing effect on the performance on the second task (cued recall). Thus, Experiment 2 did not include a recognition task before recall. Second, the use of only one type of recall cue in Experiment 1 did not allow us to fully discriminate the representational organization put forward by the DMF from other possible explanations. Thus, in addition to the discrepancy between sources, Experiment 2 also manipulated the type of cue given to participants during the recall task.

\section{Experiment 1}

The main goal of Experiment 1 was to test if discrepant statements resulted in a stronger memory representation of information sources (i.e., who said what), and in particular the connection among the respective sources of the discrepant statements. We manipulated (a) the presence of a discrepancy between the claims made by two sources and (b) the foregrounding of one of the sources at the end of the text, immediately before asking for recognition of the other source.
Consistent with the D-ISC assumption (Braasch et al., 2012), our first hypothesis was that discrepancies would increase memory for sources (the source nodes, as depicted in Fig. 1). Accordingly, we expected a main effect of discrepancy. Sources of discrepant stories should be recognized and recalled more accurately than sources of consistent stories. We also expected that readers would reduce their reading speed when presented with discrepant statements.

Our second hypothesis was that discrepancies would also enhance the integration between the sources (the SS link, as depicted in Fig. 1). The first source will be used to test the S-S link in two different ways. To test the strong form of the second hypothesis that S-S links are generated while reading, we will examine whether a restatement of this initial foregrounded source reactives or primes activation for the other source. According to this form of the second hypothesis, reading the first source presented at the end of the text should increase activation of the other source. Therefore, there should be an interaction of discrepancy and foregrounding for the recognition task. For the foregrounded condition only, the second source for the discrepant stories will be recognized more accurately and faster than the same source in the consistent stories. To test the weaker form of the second hypothesis that S-S links are generated offline only after further elaboration, we examined whether the first source would serve as a strong cue for the second source in the delayed cued-recall task. In this case, we expect a main effect of discrepancy for the recall task only.

\section{Method}

\section{Participants}

Forty psychology undergraduates from a large South American public university participated voluntarily for course credits ( $75 \%$ female, mean age $=21.35$ years, $S D=4.02$ ). All participants were native Spanish speakers and signed an 
informed consent form before taking part in the experiment. Participants were debriefed after completing the experiment.

\section{Materials}

Reading materials consisted of 16 experimental texts adapted from Braasch et al. (2012), 20 filler texts, and two practice texts. Originally extracted from online newspapers, materials described events on various topics (e.g., science, society, economy) and were written in a news report style. The adaptation included translating the original texts from French to Spanish and modifying them to fit the current design and the local context. In their final version, the texts were composed of six sections (one to two sentences each). Table 1 shows an example of an experimental story divided into sections. "Text comprehension as representation building" section contained a topical keyword in capital letters. "Discrepancies, sourcing, and the documents model framework" Section contained an introductory sentence setting the situation. "The present research" section (target section) presented two sentences composed each of a source and a content statement, along with a connector that explicitly related the two sentences. "Experiment 1" and "Experiment 2" section presented three filler sentences presenting additional information on the topic of the story, without any further mention of the sources. Finally, "General Discussion" Section presented one final sentence reintroducing information from the situation setting (i.e., the first sentence). Each section was presented to participants on a separate screen. Following Braasch et al.'s (2012) procedure, and to promote source integration during reading, the target section contained the two sentences involving the sources in the same screen. To prevent this target section from standing out, one of the sections containing filler information was also presented as a two-sentence segment. Filler and practice stories were similar to the critical stories in length and style (brief news reports), and they were also presented segmented in sections on the screen. However, filler texts were not organized around two claims, so as to prevent the participants from learning the specific structure of the critical stories.

A paper booklet was used during cued recall. The booklet contained the instructions and the recall trials (see the Memory Tasks section for further details).

Before the experiment, we conducted a pilot study to assess the target population's perception of the level of contradiction between pairs of statements in the original pool of 20 stories. Twenty-nine undergraduates who were not involved in the main studies were asked to read 10 consistent and 10 discrepant stories and to rate whether they presented a contradiction on a scale from 0 (no contradiction) to 10 (strong contradiction). Story version was counterbalanced between participants and no filler texts were used. We calculated means for consistent and discrepant versions. The four stories from the original pool presenting the smallest difference between consistent and discrepant versions were excluded, resulting in the final set of 16 two-version stories that were used in the experiments. The average ratings for consistent and discrepant versions of the stories were $2.01(S D=.66)$ and $6.9(S D=.49)$, respectively. Ratings for each story pair were contrasted with $t$ tests for independent samples, proving to be significantly different $(p<.05)$. Experimental materials therefore seemed appropriate to examine the potential effect of discrepancy on source comprehension in the target population.

\section{Design}

A 2 (discrepancy) $\times 3$ (type of cue) mixed design was used. The first factor, Discrepancy, was created by varying the discrepancy of the statements within each story (consistent/discrepant). Following Braasch et al. (2012), we changed one

Table 1 Example of an experimental story including Discrepancy and Source Foregrounding manipulations

\begin{tabular}{|c|c|c|}
\hline Section & Description & Example \\
\hline 1 & Keyword & BURNING \\
\hline 2 & Introductory line & Last night, a huge fire broke out in an old warehouse in the suburbs of Buenos Aires. \\
\hline \multirow[t]{2}{*}{3} & Source A-Content A & According to the detective, the flames were caused by a (sabotage / breakdown) in the electric circuit. \\
\hline & Source B-Content B & $\begin{array}{l}\text { Indeed/however, the journalist claimed that a pyromaniac had been arrested as he was tampering with the security } \\
\text { system. }\end{array}$ \\
\hline \multirow[t]{3}{*}{4} & Filler passage & The warehouse had been originally devoted to the storage of food products. \\
\hline & & And then for 20 years it had been used to store car pieces. \\
\hline & & Many retailers and mechanics in the area used it as storage. \\
\hline 5 & $\begin{array}{l}\text { Source A-Content A } \\
\text { (new) }\end{array}$ & $\begin{array}{l}\text { The detective mentioned that it took } 90 \text { minutes for the fire engine to reach the scene [Reinstatement condition]. } \\
\text { It took } 90 \text { minutes for the fire engine to reach the scene [Control condition]. }\end{array}$ \\
\hline 6 & Test item & Journalist \\
\hline
\end{tabular}

Note. The manipulation of Discrepancy (Line 3) is marked with italics. The manipulation of Source Foregrounding (Line 5) is indicated with brackets 
word from the first statement of Source A to make it either agree with or oppose Source B's statement. Connectors explicitly marking the relation between both sentences were also modified to indicate a confirmatory (e.g., "indeed") or an opposition relation (e.g., "however"). Braasch et al. demonstrated that including or omitting the connector did not change the overall nature of the D-ISC effect. For this study, we decided to keep the connector to reinforce the consistent or discrepant nature of the statements. The manipulation of the discrepancy is marked with italics in the sample material from Table 1.

The second factor, Source Foregrounding, was created by varying whether one of the sources was foregrounded in the last line of the text (reinstatement/control). The goal of this manipulation was to test if the reactivation of one of the source nodes would modify the accessibility of the other source node in memory, particularly in discrepant stories. This was achieved by presenting the information in the last sentence as a new statement from Source A (reinstatement) or as unreferenced information (control; see the bolded text in "Experiment 2" section in Table 1). Note that the content information in the last sentence was neutral with regard to the old statement of the source, and contained propositional arguments overlapping with the initial setting of the story (see "Discrepancies, sourcing, and the documents model framework" section), so that both conditions reinstated old information related to the section in which the target was mentioned, but only the reinstatement condition foregrounded one of the sources. A detailed description of the recognition procedure is presented in the Memory Tasks section. An example of a target source node can be seen in the Table 1 ("General Discussion" section).

Dependent variables were reading time for the target screen in milliseconds, accuracy and reaction time in milliseconds during recognition (called recognition time hereafter), and accuracy during recall. Reading times for the target screen were those corresponding to the section/screen that presented both sources and their claims (see "The present research" section). Recognition times and accuracy and recall accuracy are described below.

\section{Memory tasks}

Speeded item recognition The recognition trials followed the presentation of each text. The reader was instructed to respond yes or no to a target item as fast and accurately as possible, according to whether this item had been presented in the text. Following Glenberg, Meyer, and Lindem's (1987) procedure, the critical information was presented at the beginning of the text. Then, the last sentence of the text did or did not foreground a piece of the critical source information (i.e., the name of one the sources), as a function of the experimental manipulation. The target noun (the other source in the story) was then presented to perform the recognition trial. The answer to recognition trials was always yes for the experimental texts. Other types of target nouns (i.e., not corresponding to sources) were presented in the 20 filler texts, which included no answers. As in Glenberg et al. (1987), one third of the presentations required a no answer (i.e., for every four experimental texts there were two fillers requiring a yes and three fillers requiring a no answer). Item recognition has already been used to examine sourcing (Kim \& Millis, 2006) as well as the accessibility of story characters (McKoon, Gerrig, \& Green, 1996).

Cued recall The recall task was presented in a booklet after reading the stories and completing an intermediate task. The booklet contained the instructions and the recall trials corresponding to each experimental text (one trial per page). The target source, which was always the source mentioned in the sentence unaffected by the manipulation of the discrepancy, was cued with the topic keyword and the other source presented in the correspondent story. Participants were instructed to precisely recall the other source featured in the story by using the provided cue and were allowed to go back and forth in the booklet while responding.

The two tasks required the identification of one of the sources without any reference to the statements (to avoid influence from the source-content links during the assessment).

\section{Procedure}

Participants were tested in individual sessions. After signing the consent form, they were told that they would have to perform different activities and that the task was divided into three parts. For the first part of the experiment, participants were asked to read several texts on a computer screen, paying attention and trying to understand each text. They were also told that some of the later tasks would require recalling text information. At this time, they were also given instructions for how to perform the recognition task. Participants were told that after each text a word would appear on the screen and that they had to press the yes button if the word was present in the text, or the no button otherwise. They were asked to respond as quickly as possible, while still trying to remain accurate. To get used to the procedure, participants read two practice texts with their respective recognition trials. Presentation was self-paced, pressing the spacebar to display the respective sections of each text.

After each text but before the recognition task, three asterisks flashed in the middle of the screen for $500 \mathrm{~ms}$, indicating the area where the target item would appear. Following their response, participants were given feedback for 1 second. Reading times for the target section were recorded as the time lapse (ms) from one spacebar press to the next. Recognition times were recorded as the time (ms) between the appearance of the target item and 
the yes/no button press. Materials presentation and data recording were performed using E-Prime 1.2.

After completing the first part of the experiment, participants took the Letter-Number Sequencing subtest of WAISIII (Wechsler, 2002) as a distractor task. The test requires the participant to listen to a combined list of digits and letters and to recall the numbers in ascending order and the letters in alphabetical order. The number of items in the lists increases by one after every set of three lists; the task is discontinued when the participant fails to reorganize the three lists within a set. (Span test performance is not analyzed in this article.)

Finally, participants completed the cued-recall task. The instructions for this part were as follows:

Some of the texts you read in the first part presented two characters stating specific assertions about a certain topic. Your task now consists of recalling one of these characters for each story. To help you, we give you a topic keyword and the other character who said something in that same story. It's okay if you don't remember everything, but don't quit too fast. Sometimes memories come to mind after thinking a little bit.

Participants were allowed to go back and forth in the booklet. All the activities took place in the same room, and lasted approximately 45 minutes.

\section{Results}

We applied generalized mixed models using IBM SPSS 20.0. When the outcome variables presented a binary structure (i.e., accuracy in recognition and recall tasks), we used logistic mixed models with binomial distribution. For continuous outcome variables (i.e., chronometric data), we preferred linear models with normal distribution. We performed analyses involving chronometric data after logarithmic transformations. To facilitate interpretation, however, we use original data in milliseconds when describing the distributions.

In all cases, we entered Discrepancy (consistent, discrepant), Source Foregrounding (reinstatement, control) and their interaction as fixed factors into the model. All analyses included by-participant and by-item random intercepts. We applied the Satterthwaite correction to estimate the degrees of freedom when analyzing recognition times due to unequal number of observations. Odds ratios (OR) were used in logistic analyses to determine the effect sizes in case of significance.

\section{Reading times}

First, we performed a linear mixed analysis on the reading time data relative to the target sections to test whether participants spent more time on the discrepant stories. The target section corresponds to "The present research" section in the example presented in Table 1. No effect of Discrepancy on reading times was found, $p>.05$. Reading times (ms) for sources and their statements were similar among discrepant $(M=11,875.9, S D=5,117.1)$ and consistent stories $(M=$ $11,569.4, S D=5,138.8)$.

\section{Item recognition}

Before the inferential analyses, we examined the descriptive profile for the total trials ( 16 trials per subject, $n=640$ ) by crossing our two factors (Source Foregrounding and Discrepancy). Descriptive data are presented in Table 2. The ability to recognize items was fairly high and above chance level in all conditions. Accuracy ranged from $76 \%$ (Consistent-Reinstatement condition) to $89 \%$ (DiscrepantReinstatement condition), while mean recognition times for correct answers varied between $974 \mathrm{~ms}$ (Consistent Control) and 1,071 ms (Discrepant Reinstatement). This pattern suggests that participants performed the task in accordance to the instructions (precise and fast).

A logistic mixed analysis on accuracy (correct response vs. error) revealed that Discrepancy significantly predicted response precision during the recognition task, $F(1,636)=$ $10.66, p=.001$. Source recognition errors were more likely to occur after reading consistent stories, as compared to discrepant stories, OR $=0.35,95 \%$ CI $[0.18,0.67]$. Source Foregrounding and its interaction with Discrepancy failed to reach statistical significance, $p>.05$.

Regarding recognition times, correct answers and errors were analyzed separately. A significant effect of Discrepancy was found on errors, $F(1,67)=7.18, p=$ .009 , and a marginally significant effect in the same direction was found on correct answers, $F(1,476)=3.48, p$ $=.06$. The tendency was to take longer to respond after reading discrepant than consistent stories in both type of answers. Effects attributable to Source Foregrounding and the interaction failed to reach significance, $p>.05$.

\section{Cued recall}

Responses were coded as correct answers when participants produced the name of the target source in the corresponding trial, or when they produced a synonym clearly referring to the source in the story (e.g., reporter instead of journalist). Misidentifications (other sources from the materials), invented sources, loose categories (e.g., someone), and trials left blank were coded as errors. Correct answers represented $34.4 \%$ of the total. The other two thirds consisted of wrong answers $(40 \%)$ and trials left blank (25.6\%). The analyses presented here include the trials left blank within the error category, but 
Table 2 Descriptive statistics for accuracy (trials) and recognition times (ms) as a function of Discrepancy and Source Foregrounding (Experiment 1)

Accuracy, $n(\%)$

Recognition time, $M(S D)^{*}$

\begin{tabular}{|c|c|c|c|c|c|c|c|}
\hline Reinstatement & & Control & & Reinstatemen & & Control & \\
\hline Consistent & Discrepant & Consistent & Discrepant & Consistent & Discrepant & Consistent & Discrepant \\
\hline $122(76.2)$ & $143(89.4)$ & $128(80)$ & 137 (85.6) & $999.9(330)$ & $1071.2(459.6)$ & $974.3(316.3)$ & $1027.2(419)$ \\
\hline
\end{tabular}

*Only recognition times associated with correct trials are presented

the direction of the effects does not change when considering only the attempted trials.

Descriptive data for the sample as a function of Discrepancy is presented in Table 3. A logistic mixed analysis on source recall (correct response vs. error) indicated that Discrepancy significantly predicted response precision during the memory task, $F(1,604)=15.06, p=.0001$. The likelihood of failing in recalling the source was higher in consistent than in discrepant conditions, $\mathrm{OR}=0.41,95 \% \mathrm{CI}[0.24,0.69]$. Effects attributable to Source Foregrounding and the interaction were nonsignificant, $p>.05$.

\section{Discussion}

Our first hypothesis was that the presence of discrepancies would enhance the encoding of the sources nodes, that is, the characters issuing discrepant statements. Accordingly, we expected longer reading times and better performance in recognizing and recalling the target source after reading discrepant stories, as compared to consistent stories. Overall, results from recognition and recall support our first hypothesis, but results from reading time analysis do not.

With regard to the accuracy rates in the item-recognition task and in the recall task, the presence of discrepancies increased the number of correct responses. In the case of the item-recognition task, accuracy rates were fairly high in all conditions ( $82 \%$ on average). However, there was enough variability to show a significant difference between consistent and discrepant sources. In the case of the recall task, and as it could be expected, accuracy rates were lower than in immediate recognition in all conditions (35\% on average). Still, discrepant source names proved to be better recall cues than

Table 3 Frequencies and percentages for accuracy (trials) during the cued recall task as a function of Discrepancy (Experiment 1)

\begin{tabular}{lll}
\hline & $\begin{array}{l}\text { Consistent No. } \\
\text { of correct trials (\%) }\end{array}$ & $\begin{array}{l}\text { Discrepant No. } \\
\text { of correct trials (\%) }\end{array}$ \\
\hline $\begin{array}{l}\text { Correct responses } \\
\begin{array}{c}\text { Confusions, inventions, } \\
\text { and loose categories }\end{array}\end{array}$ & $41(27.6)$ & $125(41.1)$ \\
Trials left blank & $32(26.7)$ & $60(53.6)$ \\
\hline
\end{tabular}

consistent source names. Overall, these findings from immediate recognition and cued recall support the D-ISC claim and are in line with our first hypothesis, which predicts a memory enhancement for the sources of the discrepant statements as compared to the sources of the consistent statements. Thus, we can conclude that the presence of discrepant statements improved source memory accuracy.

However, with regard to reading times, our data showed no effects of the manipulation of discrepancy on the time spent in the critical section. Reading times were not our main focus and were considered as supplementary evidence. Nevertheless, the lack of an online discrepancy effect does not align with predictions derived from hypothesis 1 . We believe this lack of significance may be attributed to the fact that our analysis units (the critical section in each story) were fairly large. The choice of including both sentences involving the sources within the critical section, instead of using a more fine-grained segmentation, was based on previous research indicating that source-related information should be available for the reader to integrate it (e.g., Braasch et al., 2012). However, this decision may have affected the potential detection of chronometric effects within smaller analysis units, such as each separate sentence or even the source names.

Still, in relationship with our first hypothesis, there are two additional results concerning the item-recognition task that should be taken into account. First, with regard to recognition times, we also found that participants took longer to produce a response after reading discrepant rather than consistent stories. This time increase for discrepant sources was found both for correct answers and errors, thus ruling out the possibility of a speed-accuracy trade-off. One possible explanation is that discrepancies promoted distinctiveness in the mental representation. High distinctiveness would imply more separation, and therefore more components to consider when accessing the representation, thus taking more time to respond. Related research has already provided evidence in line with this idea. Kim and Millis (2006) reported priming data from a recognition task in which participants read pairs of news stories and later had to recognize sentences they had read from sentences they had not read. They found that adding sources (associating each story pair with two news agencies instead of one agency) promoted representational segregation by increasing response times, thus suggesting that their participants had created a new 
index whenever there was a shift in the sources. In brief, results from the recognition task are in agreement with our first hypothesis - that discrepancy enhances memory for sources. Furthermore, they provide evidence in line with prior research (Kim \& Millis, 2006) suggesting that sourcing promotes distinctiveness of the source nodes within the memory representation, particularly if sources disagree. Second, with regard to recognition accuracy, it is important to note that this task required participants to respond if an item had been mentioned in the text right after reading it. Although overall accuracy was relatively high, participants were more likely to respond no (i.e., "this item was not in the text") for consistent than for discrepant sources. We believe this underlines the importance of further exploring the consistent condition. So far, the focus has been put on the enhancing effect of discrepancies, but what exactly happens when the statements present overlapping arguments? Only recently has research begun to explore this question systematically (Braasch, McCabe, \& Daniel, 2016). Our recognition data specifically suggest that the source memory enhancement effect cannot be attributed exclusively to constructing source-content links, but also to the accessibility of the source nodes in the first term.

Our second hypothesis was that discrepancies would also enhance the representation of the source-source link (S-S; see Fig. 1). This S-S link could either occur spontaneously while reading or offline. In the first case, restatement of one source would prime the other source, and this would lead to better recognition in the discrepant stories compared to the consistent stories. In the second case, one source would be an effective cue for retrieving the name of the other source. Thus, there would be differences in cued recall but not in recognition. Considering that no clear evidence of the construction of S$\mathrm{S}$ links stemmed from the immediate item-recognition task, the effect observed in cued recall suggests that the integration between source nodes (i.e., who else was saying something) may have occurred as a task-guided, postreading elaboration. Thus, findings support the weaker form of our second hypotheses, which states that S-S links are generated offline only after further elaboration.

Because no support for the idea of a fully operative S-S link during reading was found, one could conjecture that discrepancies may have enhanced node accessibility (as indicated by the effect of discrepancy on accuracy) and distinctiveness (as indicated by the effect of discrepancy on recognition times). However, discrepancies may have not necessarily enhanced node linking during reading (as indicated by the lack of interaction between Discrepancy and Source Foregrounding). This claim aligns with recent research, which conceives of sourcing as a set of complex processes combining online and offline strategic activities (e.g., Braasch et al., 2012; de Pereyra, Britt, Braasch, \& Rouet, 2014). Furthermore, this claim also aligns with research in the learning and memory domain, in which it has been argued that memory tests such as cued recall need additional retrieval as compared to recognition (Nobel \& Shiffrin, 2001). This additional information may include semantically related nodes that help create links between cues and targets (e.g., Carpenter, 2011; Pyc \& Rawson, 2010).

To sum up, results from Experiment 1 support a memory advantage for contradictory sources. The results, however, only support discrepancy-induced S-S links after reading, not during reading. It could be argued that S-S linking did take place, but the online recognition task was not sensitive enough to demonstrate the linking. It could be argued, for instance, that the participants could easily recognize the sources regardless of conditions because they had just read the stories, which were fairly short. Consistent with prior research (e.g. Glenberg et al., 1987), we added a three-sentence filler passage within each text before foregrounding one of the sources to ensure that the target information was not available from the last reading cycles. However, performance was relatively high, suggesting that our online recognition task indeed lacked sensitivity. Therefore, our interpretation that linking did not take place online remains tentative and should be further explored using more demanding tasks.

There are some other limitations to this experiment. First, the use of the Letter-Number Sequencing task as a distractor activity may have resulted in differential delays or interferences depending on the participant span (i.e., the task was shorter for low-span than for high-span individuals). Although the interruption of the task presupposed that the participant had fully occupied his or her short-term resources with new information, we cannot rule out a potential confound of the time variability in the subsequent cued recall performance. Second, because recognition and recall examined the same target information (i.e., source nodes), retrieving targets during recognition may have influenced final recall memory above and beyond the reading conditions (Roediger \& Karpicke, 2006), a testing effect not attributable to sourcing processes. Moreover, this enhancement may have been accentuated by using feedback during recognition trials. Indeed, recall performance was associated with recognition performance, $\chi^{2}(1, N=608)=19.99, p=.0001$. However, a qualitative examination of the more frequently recognized items and the more frequently recalled items showed that recognizing a specific source name in the immediate task did not necessarily lead to better recall of that specific name: Only two of the six texts that showed the highest accuracy amplitude between consistent and discrepant conditions for source recognition matched the set of six texts that showed the highest accuracy amplitude for source recall, thus implying that the first task did not influence directly on the second task. Nevertheless, a possible testing effect cannot be completely ruled out and must be further considered, because it would limit our claims regarding the delayed elaboration of the S-S link. Finally, a theoretical objection could be that there are simpler explanations for the recall performance other than 
tagging source nodes into the mental representation of the text, as proposed by the DMF. For example, readers may have merely used the source cue nonspecifically, that is, not as a cue that relates A with B with an "agree/disagree" label but as a more general cue from the text, good enough to boost target retrieval. We believe this last claim requires further examination because it not only suggests an alternative explanation to our offline findings from Experiment 1 but also questions the representational organization put forward by the D-ISC claim and the DMF.

\section{Experiment 2}

The second study was conducted to provide additional support for the claim that discrepancies prompt readers to construct an integrated mental representation of the information sources, as well as to account for methodological limitations of the first study. As in Experiment 1, we used a cued-recall task to investigate whether contradictory claims would promote better recall of a target source. To avoid a possible spill-over memory effect from recognition to recall, Experiment 2 included only a delayed cued-recall task. Also, to control for potential effects of uneven intermediate delays, we changed the distractor activity for a fixed-duration task. Finally, to examine the relevance of the representational organization proposed by the DMF against other theoretical alternatives, we manipulated (a) the discrepancy between the statements of the sources and (b) the types of cues used in the recall task (assuming that some cues would work better than others, according to the representational organization suggested by the DMF).

Research on memory processes indicates that some cues are better at increasing retrieval success (see Tulving \& Craik, 2000, for a review). For example, when cue and target form a congruent, meaningful unit, cued recollection is better than when they do not (Roediger \& Adelson, 1980). The difference on recall between congruous and incongruous cues lies in their association with the target: congruous cues are or can be easily related to the target in a semantic unit, as compared to incongruous cues (Schulman, 1974). This semantic congruity effect has been well documented in the paired-items learning literature (e.g., Rajaram \& Barber, 2008), but it has not yet been used to test for assumptions regarding memory for sources within discourse representations.

As depicted in Fig. 1, the DMF proposes a specific description of how nodes are linked with each other in memory. This enables a comparison of different predictions regarding how nodes may be connected (Britt et al., 1999). The DMF predicts that when a source model is constructed, some node pairs are linked more directly (i.e., each statement with its corresponding source and the sources between them) than others (i.e., the statement of Source A with the name of Source B). The congruity effect can be used to test this prediction by comparing the linking of source-content pairs with the linking of other pairs of meaningful units.

Consider once again the example about the warehouse fire presented in Fig. 1. According to the DMF, the detective and the journalist will be represented as the origin of each statement about the cause of the fire (S-C links), and will be integrated by a rhetorical relation based on their level of agreement (S-S link; see Fig. 1). If participants base their responses on elaborating such connections, then using the statement of a specific source as a recall cue (e.g., "a pyromaniac was arrested in the act") would be as effective as using the name of the other source in that story (e.g., "the detective") to retrieve the target source node. This would be so because both pieces of information are directly connected to the target. Both cues should be more effective than the claim of the nontargeted source. In other words, participants would find it easier to retrieve the targeted node when cued with information based on "who said this" or "who else said something" (direct cues) than "who said something else than this" (indirect cue). This would be so because in the latter case participants should first retrieve their representation of the other source or the other statement and then spread to the target node, thus increasing the chances of failing to recall the target. Experiment 1 did not examine this claim directly, because only one type of cue (i.e., the name of one of the sources) was employed.

It could be argued, however, that participants in Experiment 1 based their responses merely on remembering that a certain character also belonged to that story (apart from the cued character), with no representation of this piece of information as a source, that is, without linking or tagging the statement with its reference. In this alternative scenario, the name of one of the characters (e.g., "the detective") would work better as retrieval cue than the statement (e.g., "a pyromaniac was arrested in the act"), because the reader would have not created S-C links, and the cued name would narrow the possible answers (e.g., the detective cannot be the cue and the answer at the same time), whereas the cued statement would not. Alternatively, if no differences were found between any type of cue (i.e., any statement and any source indistinctively), then a different, undifferentiated representational organization should be assumed.

To test these assumptions, we manipulated (a) the discrepancy between sources and (b) the cue given during recall. Similar to Experiment 1, we hypothesized that discrepant statements would induce an integrated representation of the sources. Hence, we expected a main effect of discrepancy: Recall should be better for discrepant than for consistent stories. Additionally, we tested three competing hypotheses for the effect of type of cues shown in Fig. 2. The first alternative hypothesis, no source tagging, (to the left in Fig. 2) proposes a minimal representation, in which characters are 

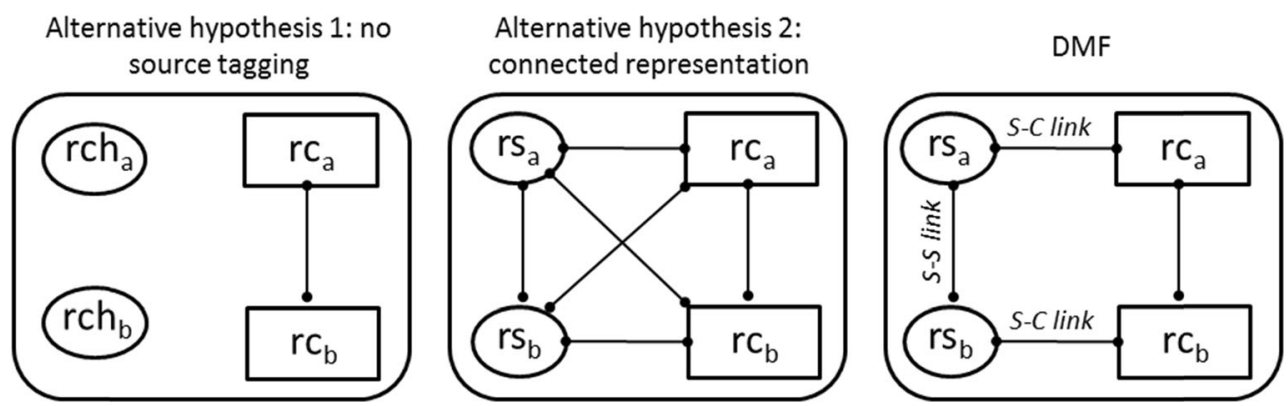

Fig. 2 Three hypotheses to the cued recall performance (Experiment 1). $\mathrm{rch}=$ representation of character; $\mathrm{rs}=$ representation of source; $\mathrm{rc}=$ representation of content

not indexed as sources. In this scenario, cueing the name of one of the characters should lead to better memory of other characters (by cancellation of the competing information) than cueing statements (which do not cancel competing information). Thus, there should be a main effect of the type of cue in which the name of the other source in the story should have better recall than either statements.

The second hypothesis, connected representation (centered in Fig. 2), proposes a hyperconnected representation, in which every piece of information is directly connected with every other piece. In this scenario, any cue (i.e., the name of one of the sources but also statements from any of the sources) would lead to similar memory for the target. Therefore, there should be no effect of cue types.

This organization is different to the more parsimonious representation proposed by the DMF (to the right in Fig. 2), in which direct and indirect connections can be assumed. As stated before, in this scenario, cues with direct link to the target (the other source and the target's statement) would enhance recall, as compared to cues indirectly linked to the target (the statement of the nontargeted source). Thus, there should be a main effect of type of cue, however, unlike the no-source tagging, the name of the other source and the statement from the targeted source should lead to better recall, as compared to the statement from the nontargeted source.

\section{Method}

\section{Participants}

Sixty psychology undergraduate students from a South American public university participated voluntarily in exchange for course credits $(82 \%$ female, mean age $=$ 20.43 years, $S D=2.83$ ). All participants signed an informed consent form before taking part in the experiment. None of the participants took part in Experiment 1.

\section{Design and materials}

A $2 \times 3$ mixed design was used. Discrepancy was treated as a within-subjects variable with two levels (consistent/discrepant), and was manipulated as in Experiment 1. Type of cue was introduced as a between-subjects variable with three levels, each one corresponding to a different cueing condition: the name of the other source in the story (Other Source Cue), the statement of the target source (Direct Statement Cue), and the statement of the nontargeted source (Indirect Statement Cue). Thus, all participants were tested for their memory of the same information piece, but the search task differed as a result of the provided cue.

Materials included a first booklet containing the same 16 experimental stories, two practice texts, and 10 out of the 20 fillers from Experiment 1. Because there was no manipulation of Source Foregrounding, the last line of the original materials from Experiment 1 was removed. Thus, each experimental text presented an introductory line, the critical section (two lines) and finished with three filler lines. Materials also included a recall booklet with one story title and one cue per page.

\section{Procedure}

Participants were randomly assigned and tested in group sessions of 20. Each group received a particular type of cue. Stories were presented in print (four random order combinations were created). As in Experiment 1, instructions were divided into three parts. For the first part, instructions were the same as in Experiment 1 (attentive reading and warning that recall of text contents may be required later). Participants were also asked to produce an alternative title for each story. This followed two purposes: to replace the item recognition task from Experiment 1 by an activity that should induce attentive reading, and to rule out the potential objection that the recall performance from Experiment 1 was influenced by the repetition of source names during the recognition task. The intermediate task consisted of the Symbol Search Task (Wechsler, 2002) instead of the WM span task used in Experiment 1. The test requires to mark a yes or no checkbox as the result of detecting a symbol within a series. Score is computed as the number of correct markings completed within 2 minutes (not analyzed here). This replacement intended to control for possible influences of the delay variation in the span task used in Experiment 1. Finally, participants 
completed the recall task by using the provided cues. Table 4 presents the three type of cue conditions applied in the aforementioned story of the warehouse fire. All participants received the same general recall instructions, similar to Experiment 1, indicating that they had to recall for some of the stories one of the two characters that had held a statement. In the other source cue condition (i.e., who else said something?), instructions added: "To help you recall, we give you the name of the other character who said something in that story." This followed Experiment 1's procedure. In the direct statement cue condition (i.e., who said this?), instructions added: "To help you recall, we give you what the character in question said." This followed Braasch et al.'s (2012) procedure. Finally, in the indirect statement cue condition (i.e., who said something else than this?) instructions added: "To help you recall, we give you what the other character in that story said." As in Experiment 1, participants were told not to quit too fast and were allowed to turn pages back and forth. Before recall, participants completed together with the experimenter an example based on one of the practice texts. Correct comprehension of the task was checked before beginning booklet completion. The activity lasted for 50 minutes approximately.

\section{Results}

Similar analyses and statistical software as in Experiment 1 were used. Discrepancy (consistent, discrepant), Type of Cue (other source, direct statement, indirect statement) and their interaction were entered as fixed factors into the model. Byparticipant and by-item intercepts were entered as random factors.
The complete distribution of responses is presented in Table 5. The coding of the responses followed the same criteria as in Experiment 1 (correct recall vs. error). Correct answers represented $22.8 \%$ of the trials in the direct statement condition, $21.6 \%$ in the other source condition, and $11.9 \%$ in the indirect statement condition (without discriminating per discrepancy condition). Trials that were left blank represented $30.9 \%$ of the trials in the direct statement group, $36.2 \%$ in the other source group, and $56.6 \%$ in the indirect statement group.

A logistic mixed analysis on the target-source recall (correct response vs. error) indicated that Discrepancy significantly predicted response precision during the memory task, $F(1,954)=$ $35.83, p=.0001$. The likelihood of correctly recalling the source was higher in discrepant than in consistent condition, $\mathrm{OR}=3.32$, $95 \%$ CI $[1.5,7.3]$. Additionally, a significant effect of Type of Cue was found, $F(2,954)=5.66, p=.004$. Participants were more accurate in the other source cue and the direct statement cue conditions than in the indirect statement cue condition, $\mathrm{OR}=$ $0.44,95 \%$ CI $[0.22,0.85]$; $\mathrm{OR}=0.39,95 \%$ CI $[0.2,0.7]$, respectively. Accuracy did not differ between the other source and the direct statement groups. The Discrepancy $\times$ Type of Cue interaction was nonsignificant, $p=.39$.

\section{Discussion}

Experiment 2 tested the influence of discrepancies on sourcing while addressing potential confounds from our first experiment. Experiment 2 also tested the efficiency of different cues to successfully recall the name of one of the sources embedded in a short news report. Our first hypothesis was that discrepant texts would increase recall as compared to consistent

Table 4 Example of instructions, cue, and correct response for the three type of cue conditions in the aforementioned example of the warehouse fire (Experiment 2)

\begin{tabular}{|c|c|c|c|}
\hline & Other source cue & Direct statement cue & Indirect statement cue \\
\hline $\begin{array}{l}\text { General instruction } \\
\text { (common to all } \\
\text { conditions) }\end{array}$ & \multicolumn{3}{|c|}{$\begin{array}{l}\text { "Some of the texts you read in the first part presented two characters making specific assertions about a certain topic. Your task now } \\
\text { consists of recalling one of these characters for each story. It's normal if you don't recall everything, but don't quit too fast. } \\
\text { Sometimes memories come to mind after some thinking." }\end{array}$} \\
\hline $\begin{array}{l}\text { Specific instruction } \\
\text { (unique to each } \\
\text { type } \\
\text { of cue condition) }\end{array}$ & $\begin{array}{l}\text { "To help you recall, we give you the } \\
\text { other character who said } \\
\text { something in that story." }\end{array}$ & $\begin{array}{l}\text { "To help you recall, we give you what the } \\
\text { character in question said." }\end{array}$ & $\begin{array}{l}\text { "To help you recall, we give you what the } \\
\text { other character in that story said." }\end{array}$ \\
\hline $\begin{array}{l}\text { Cue (based on the } \\
\text { warehouse fire } \\
\text { example from } \\
\text { Table 1) }\end{array}$ & $\begin{array}{l}\text { Title: FIRE } \\
\text { Character 1: detective } \\
\text { Character 2?: }\end{array}$ & $\begin{array}{l}\text { Title: FIRE } \\
\text { Character's statement: "A pyromaniac has } \\
\text { been arrested as he was tampering with } \\
\text { the security system." } \\
\text { Character?: }\end{array}$ & $\begin{array}{l}\text { Title: FIRE } \\
\text { Other character's statement: "The flames } \\
\text { were caused by a (sabotage / breakdown) } \\
\text { in the electric circuit." } \\
\text { Character?: }\end{array}$ \\
\hline $\begin{array}{l}\text { Correct response } \\
\text { (based on the } \\
\text { warehouse fire } \\
\text { example from } \\
\text { Table 1) }\end{array}$ & Journalist & Journalist & Journalist \\
\hline
\end{tabular}


Table 5 Frequencies and percentages for the different response types obtained during the cued recall task, as a function of Discrepancy and Type of Cue (Experiment 2)

\begin{tabular}{|c|c|c|c|c|c|c|}
\hline & \multicolumn{2}{|c|}{ Other source cue $-n(\%)$} & \multicolumn{2}{|c|}{ Direct statement cue- $n(\%)$} & \multicolumn{2}{|c|}{ Indirect statement cue- $n(\%)$} \\
\hline & Consistent & Discrepant & Consistent & Discrepant & Consistent & Discrepant \\
\hline Correct responses & $17(10.6)$ & $52(32.5)$ & $25(15.6)$ & $48(30)$ & $11(6,9)$ & $27(16.9)$ \\
\hline Confusions, inventions, and loose categories & $79(49.4)$ & $56(35)$ & $84(52.5)$ & $64(40)$ & $46(28.7)$ & $55(34.4)$ \\
\hline Trials left blank & $64(40)$ & $52(32.5)$ & $51(31.9)$ & $48(30)$ & $103(64.4)$ & $78(48.7)$ \\
\hline
\end{tabular}

texts. In line with this claim, and similar to Experiment 1, we found a main discrepancy effect associated with recall, thus adding support to the D-ISC predictions regarding memory for disagreeing sources. Our second hypothesis was that direct cues (the name of the other source and the targeted source's statement) would work as better recall cues to access the target node than an indirect cue (the statement from the nontargeted source). This hypothesis was based in the representational organization of sources and contents depicted by the DMF, in which a particular source node can be directly accessed via another source node (the S-S link), and via the contents associated to it (the S-C link). As expected, we found that direct cues (other source and direct statement cues) worked better at promoting recall than the indirect cue. Furthermore, trials left blank were almost twice more frequent in the indirect statement condition than in the direct statement condition. An inspection of Table 5 reinforces this idea: when the information was discrepant, the percentage of confusion errors among the three groups was similar $(M=36.4)$; however, the percentage of trials left blank in the indirect statement cue condition $(48.7 \%)$ was higher than their equivalents in the direct cueing conditions (other source cue: $32.5 \%$; direct statement cue: $30.0 \%$ ). Considering that all groups were equally encouraged to fulfill the task, the augmentation of trials left blank when an indirect cue was provided suggests that participants in this group may have found it particularly difficult to recall the target, as predicted by the DMF. This idea is also supported by the fact that the proportions of trials left blank for the two direct cues were similar to the recall pattern observed in Experiment 1 (about one third of the trials), thus indicating that the indirect cue may have operated differently over retrieval as compared to the direct cues.

Also, one of the goals of Experiment 2 was to control for confounds in the first experiment: Time variability in the intermediate task and a possible influence on final recall from practice retrieving information during recognition. Whereas the influence of these confounds cannot be ruled out, the fact that Experiment 2 mirrored the recall pattern from Experiment 1 suggests that any potential influence would not be sufficient to account for the D-ISC effect observed in the latter. An inspection of the accuracy rates from both experiments (Tables 3 and 5) shows, indeed, that the percentage of correct responses was higher in Experiment 1 (34.3\%) than for the equivalent condition from Experiment 2 (other source cue: $21.5 \%$ ). Thus, practice retrieval may have very likely influenced Experiment 1 's performance. However, this testing effect seemed to affect more the accuracy rate in the consistent (Experiment 1: $27 \%$; Experiment 2: $10.6 \%$ ) than in the discrepant condition (Experiment 1: $41.1 \%$; Experiment 2: $32.5 \%$ ).

To sum up, results from Experiment 2 support an extension of the D-ISC assumption, used so far to account for the S-C component of the documents model to incorporate the construction of S-S links in long-term memory.

\section{General Discussion}

The main goal of this study was to extend our theoretical understanding of text comprehension by examining readers' processing of texts presenting discrepant accounts of a situation. We summarize the main findings with respect to our theoretical predictions, and we discuss their implications for a general theory of source and content integration during text comprehension.

\section{The D-ISC effect}

Both experiments showed that a discrepancy between sources will increase memory for source information. Overall, we found evidence that the enhancement effect attributed to discrepancy was found both when assessing source memory with immediate recognition (Experiment 1) as well as with delayed recall (Experiments 1 and 2). These results are consistent with previous studies (Braasch et al., 2012; de Pereyra, Britt, et al., 2014; Kammerer et al., 2014; Rouet et al., 2016) and provide further support for the discrepancy-induced source comprehension assumption (D-ISC; Braasch et al., 2012) that stems from the documents model framework (DMF; Britt et al., 1999; Perfetti et al., 1999). According to the DMF, these source-content (S-C) links allow the reader to create a coherent representation when there are discrepancies that could not otherwise coexist. In our example, either the fire was a criminal purposeful act or an accident. These are mutually exclusive, and without the sources the story would not be coherent. Thus, in terms of empirical contributions, our findings align with previous research by showing a source memory 
enhancement as a function of the discrepancy of the assertions while also extending it to an item recognition task. Whether discrepancies that are easier to reconcile would still trigger source comprehension is still an open empirical question. According to the D-ISC claim, readers should first perceive that the facts are incompatible for them to use the sources to regulate the perceived incoherence. Thus, if a reader perceives that the discrepant statements may coexist (e.g., two different evaluative responses to a painting), then a reduction of the sourcing effect could be expected. Indeed, Rouet et al. (2016) have found that readers use a variety of strategies to summarize discrepant stories, ranging from source citation to hedging to reconciling. Further work should be done to better understand what triggers readers' perceptions of a discrepancy and how textual discrepancies are to be explained.

\section{The construction of S-S links}

We also investigated the extent to which readers create connections between sources. We tested three mutually exclusive hypotheses. According to the no-source tagging hypothesis, readers may not connect information to who said it (S-C link) or between sources (S-S link). According to the hyperconnected representation hypothesis, readers represent not only connections between what the sources say and between sources, they also represent connections to assertions that the sources they disagree with say. Finally, according to the DMF, readers represent who said what (S-C) and which sources agree or disagree (S-S). We found that one source did in fact cue the recall of the other source better than the topic (Experiment 1) or the other source's assertion (Experiment 2). This finding does not support the no-source tagging hypothesis. We also found that a source's assertion cued the recall of that source, but not the recall of the other source (Experiment 2 ). This finding does not support for the hyperconnected representation hypothesis. This limited sourcing tagging is consistent with other studies indicating that task (e.g., Keck et al., 2015; Stadtler et al., 2014; Steffens, Britt, Braasch, Strømsø, \& Bråten, 2014) and individual differences (e.g., Barzilai \& Eshet-Alkalai, 2015; Kammerer et al., 2013; von der Mühlen, Richter, Schmid, Schmidt, \& Berthold, 2016) play a role in the amount and quality of source tagging. The only hypothesis supported by these recall findings is the DMF. It seemed more likely for our participants to represent both who said what and who agreed/disagreed than who didn't say what.

Another goal was to examine whether connections between disagreeing sources can influence the representation immediately after reading the relevant information, as measured by the increased activation of one source due to a restatement prime. However, accessibility may have not been sufficient to create the S-S link, as indicated by the lack of facilitation on the recognition of one source by the reintroduction of the other. Our data suggests that discrepant sources were more accessible, although not necessarily interconnected, in memory tasks occurring immediately after reading. On the contrary, we found that participants were able to use the name of one of the discrepant sources as a cue to better recall the name of the other information source, as long as they could elaborate what they had read (Experiments 1 and 2). This pattern of findings suggests that discrepancies promoted the construction of S-S links, but not during reading.

In relationship with that last claim, one salient aspect from our findings is the impact of the delayed task on sourcing. As observed in Experiments 1 and 2, participants were able to use one source to recall the other one in delayed tasks. Furthermore, Experiment 2 suggests that participants found it harder to recall the same target information depending on the provided cue. It is important to note that participants were presented with the instruction (and the cue) after reading, so that an initial, potentially similar memory representation had already been codified by the three groups receiving different cues. Once again, we believe this highlights the importance of the postreading phase in sourcing, implying that goals represented after reading could retrospectively influence discourse elaboration.

But, what is the exact nature of these "reflective" processes that may reelaborate the already encoded source nodes into an integrated unit? Research and theory within the wider spectrum of memory has proposed two basic operations to account for the semantic reconstructions associated to recollection (e.g., Dobbins, Foley, Schacter, \& Wagner, 2002): retrieval cue specification (a self-generated consideration of how likely it is that a cue links with different, potential candidates in memory) and recollection monitoring (an evaluation of the relevance of a specific retrieved piece of information for a particular task). Future research efforts should examine if a generalization of these processes into the more specific domain of sources' representation during reading can be supported empirically, or even if the effect of delay is associated to consolidation processes.

\section{Limitations}

There are some limitations to our conclusions. First, the fact that no spontaneous construction of S-S links was found as a function of text coherence (Experiment 1) was unexpected. As a tentative explanation, it is possible that the foregrounding sentence, which rementioned one of the sources but talking about a different point (that the two sources did not disagree about), was not a strong enough cue to reactivate the representation of the other source. One simple factual disagreement may not be enough to mark that two sources always disagree. The sources could agree on many other things, so their being close may be only contingent on the particular issue they disagree about. Because we were concerned with assessing the S-S link, we specifically avoided references to the initial assertions 
when reinstating the target source node; however, this strategy may have affected the expected source-to-source priming.

That said, our distinction of online and offline sourcing processes should not be taken categorically. Whether such processes occur during or after reading may very likely depend on the many factors that modulate comprehension. We suggest that the representation of source information (attending to and encoding sources, establishing links between sources and claims, determining if sources agree or disagree, etc.) is not an all-or-none process. Some aspects of this organization may emerge relatively fast whereas other may require a delay. Some may be available to a broad range of readers while others may depend on the readers' expertise in the domain or their prior knowledge of the topic. The idea that readers' responses to conflicts in texts can involve several steps or degrees is shared by current task-oriented reading frameworks (e.g., Kendeou \& O'Brien, 2014; Stadtler \& Bromme, 2014). For example, the content-source integration model (Stadtler \& Bromme, 2014) argues that dealing with discrepant sources is part of a greater set of integration processes, which include identifying the conflict, regulating it and, eventually, resolving it. We believe our data are in line with these proposals, underlining the complex nature of sourcing strategies, how source information is represented in memory, and how it interacts with task constraints.

Another related limitation regards text length and the generalization of the results to multiple texts. The documents model framework (Britt et al., 1999; Perfetti et al., 1999) was originally formulated to account for readers' comprehension of multiple document sets. The use of short texts instead of multiple extended documents may have contributed to the specific pattern of effects. For instance, the use of embedded sources (characters), their proximity and the use of explicit connectors to mark their relationship may have enhanced node linking.

We believe these limitations should definitely be kept in mind when generalizing the results. However, although source tagging was initially studied in the context of multiple text comprehension, there is mounting evidence that it takes place in the context of simple text reading (Braasch et al., 2012; de Pereyra, Britt, et al., 2014) or embedded references within multiple texts (Strømsø, Bråten, Britt, \& Ferguson, 2013). Our study aimed at contributing some additional evidence that sourcing is one of the mechanisms whereby readers deal with the perceived discrepancy of two claims. In contrast with most multiple text comprehension experiments, our concise items allowed us to use a repeated-measures design and therefore control for several confounding variables that may arise when using longer texts. This design enabled us to clearly delimitate discrepancy as one text factor that induces source tagging (S-C and S-S links).
The specificity of the materials used in our experiments, however, precludes any direct generalization of the findings to other types of texts. Readers may find it more difficult to relate information sources in longer or even in multiple texts, particularly if the distance between source features and arguments increases. This would also include the case in which sources are external authors of a document rather than embedded characters. De Pereyra, Britt, et al. (2014), for example, have reported that readers remember sources involved in the situation (e.g., a witness) better than remote sources (e.g., someone commenting the topic from a distance). A similar effect has also been reported by Graesser, Bowers, Olde, and Pomeroy (1999) regarding the representation of agents associated with a text. At the same time, we cannot rule out the possibility that source-to-source linking develops strategically during reading under some conditions. It will be of interest for researchers to further specify the moderation of the D-ISC effect-and in particular of the S-S linking-in longer materials, when source features are more salient, when they vary in competence or benevolence, or when the attributed importance to the described events is higher.

Finally, because initial instructions in both experiments indicated that a memory task would occur later on, participants may have perceived the reading task as content memorization. Although reading instructions also said to pay attention and try to understand, a hypothetical memorization strategy cannot be ruled out, even if it would still not account for the differences observed between conditions. Thus, results reported here should not be directly generalized to situations in which readers are not anticipating an eventual retrieval of text information.

\section{Implications and future research}

In line with prior research, our data indicated that readers have some representation of source information, although they do not necessarily engage in sourcing activities in every reading act. Because of this nonobligatory nature, examining the conditions that increase the likelihood of strategically attending to and using source information is important. This study provides evidence that a semantic opposition between two pieces of content information within a text can actually affect the extent to which readers integrate different aspects of information sources in memory. When we witness events or evaluate claims, there can be multiple perspectives. Texts and assertions can be affected by the source's knowledge, bias, access to information, and so on. Texts are not a perfect correspondence to reality. In these cases, S-S and S-C links allow us to create a coherent representation of a situation described and interpreted from multiple accounts. From different perspectives, sources will present slightly different (unique or weighted differently) versions for actually contradictory information. To be able to represent dissimilar views coherently, S-S and S- 
$\mathrm{C}$ links are needed; therefore, text discrepancies constitute one relevant factor that increase the likelihood of sourcing.

In particular, constructing S-S links may play a significant role when the reader is doing more than representing a source's statement or information. Integrating two or more sources as a function of their level of disagreement allows the reader to explain differences in perspective and to evaluate what to believe. Because the evaluative processes were not the focus in this research, future efforts should determine the relative weight of S-S links on accepting or rejecting specific assertions, as compared to other components of the documents model. Similarly, future efforts should consider how beliefconsistency biases may influence the construction of these links. Take for example the case in which several instances corroborate the same information before introducing a discrepancy. Would this corroboration lead to less S-S linking as a cause of perceiving that the evidence is stronger?

Future research efforts should also examine whether further assumptions within the DMF can be integrated within a rich history in memory research. The general frame provided by memory models of text comprehension, as well as the distinction between what recognition and recall tasks differentially afford in terms of memory processes' sensitivity, was key to this study. We think the more general realm of memory research can serve as a basis to generate new predictions and expand the current state of the art within the domain of sourcing in reading, as it has for other components of the representation of discourse (Goldman et al., 2007).

We believe this last claim can also have an impact in applied contexts. Interventions that promote sourcing should not only focus on prereading training but should also emphasize the rhetorical organization of discourse during postreading sessions. According to our results, readers may develop more or less of a rhetorical dimension of the text later; depending on the paths they use to access their memory representation.

\section{References}

Albrecht, J. E., \& O’Brien, E. J. (1993). Updating a mental model: Maintaining both local and global coherence. Journal of Experimental Psychology: Learning, Memory and Cognition, 19, 1061-1070. doi:10.1037/0278-7393.19.5.1061

Barzilai, S., \& Eshet-Alkalai, Y. (2015). The role of epistemic perspectives in comprehension of multiple author viewpoints. Learning and Instruction, 36, 86-103. doi:10.1016/j. learninstruc.2014.12.003

Braasch, J., McCabe, R. M., \& Daniel, F. (2016). Content integration across multiple documents reduces memory for sources. Reading and Writing. doi:10.1007/s11145-015-9609-5. Advance online publication.

Braasch, J., Rouet, J.-F., Vibert, N., \& Britt, M. A. (2012). Readers' use of source information in text comprehension. Memory and Cognition, 40, 450-465. doi:10.3758/s13421-011-0160-6
Britt, M. A., Perfetti, C. A., Sandak, R., \& Rouet, J.-F. (1999). Content integration and source separation in learning from multiple texts. In S. R. Goldman, A. C. Graesser, \& P. van den Broek (Eds.), Narrative comprehension, causality, and coherence: Essays in honor of Tom Trabasso (pp. 209-233). Mahwah: Erlbaum.

Britt, M. A., Richter, T., \& Rouet, J.-F. (2014). Scientific literacy: The role of goal-directed reading and evaluation in understanding scientific information. Educational Psychologist, 49, 104-122. doi:10.1080 /00461520.2014.916217

Britt, M. A., \& Rouet, J. F. (2012). Learning with multiple documents: Component skills and their acquisition. In M. J. Lawson \& J. R. Kirby (Eds.), The quality of learning: Dispositions, instruction, and mental structures. New York: Cambridge University Press.

Britt, M. A., Rouet, J.-F., \& Braasch, J. L. G. (2013). Documents experienced as entities: Extending the situation model theory of comprehension. In M. A. Britt, S. R. Goldman, \& J.-F. Rouet (Eds.), Reading: From words to multiple texts (pp. 160-179). New York: Routledge, Taylor \& Francis Group.

Carpenter, S. K. (2011). Semantic information activated during retrieval contributes to later retention: Support for the mediator effectiveness hypothesis of the testing effect. Journal of Experimental Psychology: Learning, Memory, \& Cognition, 37, 1547-1552. doi: $10.1037 / \mathrm{a} 0024140$

de Pereyra, G., Belkadi, S., Marbach, L., \& Rouet, J. F. (2014). Do teenage readers use source information when faced with discrepant information? Chicago: Paper presented at the 24th annual meeting of the Society for Text and Discourse.

de Pereyra, G., Britt, M. A., Braasch, J. L. G., \& Rouet, J.-F. (2014). Reader's memory for information sources in simple news stories: Effects of text and task features. Journal of Cognitive Psychology, 26, 187-204. doi:10.1080/20445911.2013.879152

Dobbins, I. G., Foley, H., Schacter, D. L., \& Wagner, A. D. (2002). Executive control during episodic retrieval: Multiple prefrontal processes subserve source memory. Neuron, 35, 989-996. doi:10.1016 /S0896-6273(02)00858-9

Dooling, D. J., \& Christiaansen, R. E. (1977). Levels of encoding and retention of prose. Psychology of Learning and Motivation, 11, 139. doi:10.1016/S0079-7421(08)60474-0

Gernsbacher, M. A. (2014). Internet-based communication. Discourse Processes, 51, 359-373. doi:10.1080/0163853X.2014.916174

Glenberg, A., Meyer, M., \& Lindem, K. (1987). Mental models contribute to foregrounding during text comprehension. Journal of Memory and Language, 26, 69-83. doi:10.1016/0749-596X(87)90063-5

Goldman, S. R., Golden, R., \& van den Broek, P. (2007). Why are computational models of text comprehension useful? In F. Schmalhofer \& C. Perfetti (Eds.), Higher-level language processes in the brain (pp. 27-52). Mahwah: Erlbaum.

Graesser, A. C., Bowers, C., Olde, B., \& Pomeroy, V. (1999). Who said what? Source memory for narrator and character agents in literary short stories. Journal of Educational Psychology, 91(2), 284-300. doi:10.1037/0022-0663.91.2.284

Johnson, M. K., Hashtroudi, S., \& Lindsay, D. S. (1993). Source monitoring. Psychological Bulletin, 114, 3-28. doi:10.1037/00332909.114.1.3

Kammerer, Y., Amann, D. G., \& Gerjets, P. (2015). When adults without university education search the Internet for health information: The roles of Internet-specific epistemic beliefs and a source evaluation intervention. Computers in Human Behavior, 48, 297-309. doi:10.1016/j.chb.2015.01.045

Kammerer, Y., Bråten, I., Gerjets, P., \& Strømsø, H. (2013). The role of Internet-specific epistemic beliefs in laypersons' source evaluations and decisions during Web search on medical issue. Computers in Human Behavior, 29, 1193-1203. doi:10.1016/j.chb.2012.10.012

Kammerer, Y., Kalbfell, E., \& Gerjets, P. (2014). How contradictions between Web pages stimulate source evaluation. Valencia: Paper presented at the Workshop on Multiple Document Literacy. 
Keck, D., Kammerer, Y., \& Starauschek, E. (2015). Reading science texts online: Does source information influence the identification of contradictions within texts? Computers \& Education, 82, 442-449. doi:10.1016/j.compedu.2014.12.005

Kendeou, P., \& O'Brien, E. J. (2014). The Knowledge Revision Components $(\mathrm{KReC})$ framework: Processes and mechanisms. In D. N. Rapp \& J. L. G. Braasch (Eds.), Processing inaccurate information: Theoretical and applied perspectives from cognitive science and the educational sciences (pp. 353-377). Cambridge: MIT Press.

Kendeou, P., Smith, E. R., \& O'Brien, E. J. (2013). Updating during reading comprehension: Why causality matters. Journal of Experimental Psychology: Learning, Memory, \& Cognition, 39, 854-865. doi:10.1037/a0029468

Kim, H.-J. J., \& Millis, K. (2006). The influence of sourcing and relatedness on event integration. Discourse Processes, 41, 51-65. doi:10.1207/s15326950dp4101_4

Kintsch, W. (1998). Comprehension: A paradigm for cognition. New York: Cambridge University Press.

McKoon, G., Gerrig, R. J., \& Greene, S. B. (1996). Pronoun resolution without pronouns: Some consequences of memory based text processing. Journal of Experimental Psychology: Learning, Memory, and Cognition, 22, 919-932. doi:10.1037/0278-7393.22.4.919

McKoon, G., \& Ratcliff, R. (1980). Priming in item recognition: The organization of propositions in memory for text. Journal of Verbal Learning and Verbal Behavior, 19, 369-386. doi:10.1016/S00225371(80)90267-4

McKoon, G., \& Ratcliff, R. (1984). Priming and on-line text comprehension. In D. E. Kieras \& M. A. Just (Eds.), New methods in reading comprehension research (pp. 119-128). Mahwah: Erlbaum.

Myers, J. L., \& O’Brien, E. J. (1998). Accessing the discourse representation during reading. Discourse Processes, 26(2-3), 131-157. doi:10.1080/01638539809545042

Nobel, P. A., \& Shiffrin, R. M. (2001). Retrieval processes in recognition and cued recall. Journal of Experimental Psychology: Learning, Memory, and Cognition, 27, 384-413. doi:10.1037/02787393.27.2.384

O’Brien, E. J., \& Albrecht, J. E. (1992). Comprehension strategies in the development of a mental model. Journal of Experimental Psychology: Learning, Memory and Cognition, 18, 777-784. doi:10.1037/0278-7393.18.4.777

Paul, J., de Pereyra, G., Stadtler, M., Potocki, A., Salmeron, L., MacedoRouet, M., ... Rouet, J.-F. (2014). MD-SKILLS: An international project to study and foster 9th Grade students' multiple document literacy. Paper presented at the Workshop on Multiple Document Literacy, Valencia, Spain.

Perfetti, C. A., Rouet, J.-F., \& Britt, M. A. (1999). Towards a theory of documents representation. In H. van Oostendorp \& S. R. Goldman (Eds.), The construction of mental representations during reading. Mahwah: Erlbaum

Pyc, M. A., \& Rawson, K. A. (2010). Why testing improves memory: Mediator effectiveness hypothesis. Science, 330, 335. doi:10.1126 /science.1191465

Rajaram, S., \& Barber, S. J. (2008). Retrieval processes in memory. In H. L. Roediger III (Ed.), Cognitive psychology of memory. Vol. 2 of Learning and memory: A comprehensive reference (pp. 261-283). Oxford: Elsevier.

Roediger, H. L., \& Adelson, B. (1980). Semantic specificity in cued recall. Memory \& Cognition, 8, 65-74. doi:10.3758/BF03197553
Roediger, H. L., \& Karpicke, J. D. (2006). The power of testing memory: Basic research and implications for educational practice. Perspectives on Psychological Science, 1, 181-210. doi:10.1111 j. 1745-6916.2006.00012.x

Rouet, J.-F. (2006). The skills of document use: From text comprehension to Web-based learning. Mahwah: Erlbaum. doi:10.4324 /9780203820094

Rouet, J.-F., Le Bigot, L., de Pereyra, G., \& Britt, M. A. (2016). Whose story is this? Discrepancy triggers readers' attention to source information in short narratives. Reading and Writing. Advance online publication.. doi:10.1007/s11145-016-9625-0

Salmerón, L., Kammerer, Y., \& García-Carrión, P. (2013). Searching the Web for conflicting topics: Page and user factors. Computers in Human Behaviour, 29, 2161-2171. doi:10.1016/j.chb.2013.04.034

Schulman, A. I. (1974). Memory for words recently classified. Memory \& Cognition, 2, 47-52. doi:10.3758/BF03197491

Stadtler, M., \& Bromme, R. (2014). The content-source integration model: A taxonomic description of how readers comprehend conflicting scientific information. In D. N. Rapp \& J. Braasch (Eds.), Processing inaccurate information: Theoretical and applied perspectives from cognitive science and the educational sciences (pp. 379-402). Cambridge: MIT Press.

Stadtler, M., Scharrer, L., Skodzik, T., \& Bromme, R. (2014). Comprehending multiple documents on scientific controversies: Effects of reading goals and signaling rhetorical relationships. Discourse Processes, 51(1-2), 93-116. doi:10.1080/0163853 X.2013.855535

Steffens, B., Britt, M. A., Braasch, J. L., Strømsø, H., \& Bråten, I. (2014). Memory for scientific arguments and their sources: Claim-evidence consistency matters. Discourse Processes, 51, 117-142. doi:10.1080/0163853X.2013.855868

Strømsø, H. I., \& Bråten, I. (2014). Students' sourcing while reading and writing from multiple documents. Nordic Journal of Digital Literacy, 9, 92-111. doi:10.1111/bjep.12005

Strømsø, H. I., Bråten, I., Britt, M. A., \& Ferguson, L. E. (2013). Spontaneous sourcing among students reading multiple documents. Cognition and Instruction, 31, 176-203.

Tulving, E., \& Craik, F. I. M. (2000). The Oxford handbook of memory. New York: Oxford University Press.

van den Broek, P., Rapp, D. N., \& Kendeou, P. (2005). Integrating memory-based and constructionist processes in accounts of reading comprehension. Discourse Processes, 39(2-3), 299-316. doi:10.1207/s15326950dp3902\&3_11

van den Broek, P., Young, M., Tzeng, Y., \& Linderholm, T. (1999). The landscape model of reading. In H. van Oostendorp \& S. R. Goldman (Eds.), The construction of mental representations during reading (pp. 71-98). Mahwah: Erlbaum.

van Oostendorp, H. (2002). Updating mental representations during reading scientific text. In J. Otero, J. A. Leon, \& A. C. Graesser (Eds.), The psychology of science text comprehension (pp. 417-436). Mahwah: Erlbaum.

von der Mühlen, S., Richter, T., Schmid, S., Schmidt, E. M., \& Berthold, K. (2016). Judging the plausibility of arguments in scientific texts: A student-scientist comparison. Thinking \& Reasoning, 22, 221-249. doi:10.1080/13546783.2015.1127289

Wechsler, D. (2002). WAIS-III. Escala de inteligencia para adultos de Wechsler (3rd ed.). Buenos Aires: Paidós. 